Published in Interprofessional Journal of Care 29 (6), 610-615.

\title{
Boundary Work in Inter-agency and Interprofessional Client Transitions
}

\author{
Sirpa Saario, Kirsi Juhila, and Suvi Raitakari
}

Correspondence: sirpa.saario@uta.fi, University of Tampere, Finland.

\begin{abstract}
This article analyses the accomplishment of boundary work performed by professionals engaged in inter-agency collaboration. As a means of building authority within a particular field, boundary work is found to be a common feature of most professional practices. By analysing the talk of Finnish professionals who work in the field of supported housing in mental health, the article investigates the ways professionals - as collective representatives of their service - talk about doing boundary work when transferring their clients to another agency. The study drew on the principles of exploratory case study design and ethnomethodology. A key finding from the analysis of professionals' focus groups and team meetings indicated that boundary work is employed when disputes arise between supported housing and collaborating agencies. The article goes on to suggest that professionals accomplish boundary work by rhetorically presenting themselves as holders of “day-to-day evidence” of clients' mundane living skills and serious ill-health. The paper concludes by arguing that in inter-agency collaboration, boundary work building on day-to-day evidence is used to influence the decision on the most appropriate living arrangement for the client. Boundary work is also used for boosting the authority of professionals as representatives of a relatively new and fixed-term agency in the service system.
\end{abstract}

Keywords: boundary work, inter-agency collaboration, mental health, supported housing, Finland This article is part of the research project 'Responsibilization of Professionals and Service Users in Mental Health Practices', funded by the Academy of Finland. 


\section{Introduction}

Initially, the concept of boundary work was developed by Gieryn (1983) who used the term to describe how scientists rhetorically distinguished science from non-science. Later, Fournier (2000, p. 69) has defined boundary work as a means by which professionals aim to constitute knowledge as the basis upon which they can build their authority and exclusivity. More generally, boundary work has been described as processes by which boundaries, demarcations or other divisions are constructed and negotiated (Wikström 2008, p. 60).

Boundary work is closely linked to the concept of jurisdiction which signifies a legitimate activity within a particular field. The term "occupational jurisdiction" employed by Abbott (1988) refers to having exclusive rights in terms of one's profession. As such, jurisdiction forms the link between an occupation and its work, leading to the existence of professions. In empirical work building on Abbott's $(1995,1988)$ notions, boundary work is usually approached as exclusive rights in terms of one's profession, either within occupational groups or individual professionals (e.g. Allen 2000, 2001; Håland 2012). While boundary work is usually performed to establish hierarchies among professions, the interprofessional context may also encourage the crossing of boundaries and the associated reframing of problems, as well as shared understanding and commonly agreed goals among professions (Gachoud, Albert, Kuper, Stroud, \& Reeves, 2012; Sanders \& Harrison; Slembrouck \& Hall (2014).

In this article, we approach boundary work slightly differently than as a means of occupational jurisdiction in Abbott's sense. Instead of analysing how boundary work takes place within individual professionals or occupational groups, we focus on boundary work as a means of obtaining what we term "organisational jurisdiction" - professionals claiming their authority over a certain domain of practice, primarily as representatives of their agency. "Organisational jurisdiction" is not an established concept but, drawing from Wikström (2008, p. 60), we use it here 
to describe the strategies by which a group attempts to become more influential in professional arenas by mutually accomplishing their legitimation over a particular field. As Riesch (2010, p. 3) states, Gieryn's (1983) metaphor of boundary work lends it also to those analyses where social groups draw boundaries to differentiate themselves from others. In other words, we study professionals' performances of boundary work as strategies to reproduce their organisation as "an orderly entity" (Llewellyn 1994).

Building on boundary work as a means of obtaining organisational jurisdiction, this article sets out to analyse the rhetorical strategies by which professionals aim to define their authority over client transitions, in relation to collaborative agencies. The study concentrates on a communitybased mental health practice, and more specifically on the professionals as they discuss client transitions between different agencies. Transitions are a key feature in mental health as there are currently a wide range of inter-agency stakeholders involved in the provision of services. This results from the emphasis on community care which has led to decentralised mental health services in European welfare states (Knapp, Beecham, McDaid, \& Matosevic, 2011).

For mental health professionals, decentralised services signify engaging in more interagency work: professionals are under pressure to collaborate (Mossberg, 2013). To manage the frequent transitions of clients, they need to assess which placement would be most appropriate for each client, and at the same time, need to communicate successfully with various agencies to make these transitions happen. Rose (1999, p. 261) illustrates these demands by the shift in mental health professionals' responsibilities: professionals continue to carry out clinical work like they have done before, "but the key judgement that must be made is a different one - what should be done with this person, should he or she be sent to this institution or to that, to this hostel or that sheltered housing scheme, back into the community or back into prison". 
One important form of community care in mental health field is supported housing (Fakhoury \& Priebe, 2002). The setting of this article is a supported housing project (henceforth, the Project), which can be described as a "half way agency" as it collaborates both with the services from where the clients are coming and those to where the clients are heading. The Project is a new service with less established remits and pursues to establish its place in the local service system. The Project's professionals aim to strengthen their role among more traditional services such as psychiatric outpatient clinics, hospitals, and long-term residential homes. Thus, the Project can be considered an ideal context for studying boundary work from the point of view of organisational jurisdiction: as an interprofessional team, professionals in the supported housing project aim to make distinct their service from other agencies in the field.

\section{Methods}

The study drew on the principles of exploratory case study design (Yin, 1994). The design enabled a detailed examination of two rather novel cases in Finnish supported housing, i.e. two service periods of Project. Our exploration concerns particularly the accomplishment of boundary work in interaction, a domain rarely addressed in previous research, as noted by Slembrouck and Hall (2014). To analyse boundary work strategies in interaction of professionals, we utilise Garfinkel's (1967) ethnomethodological idea to study human action and reasoning as they take place in ordinary everyday practices.

Study setting

The setting for this study is the Project (anonymised) in Finland that carries out intensive, short-term service for people diagnosed with schizophrenia. Four service periods are carried out yearly, each lasting for three months. In the Project the clients are provided supported housing in single rooms in a large terraced house, with project staff available during weekdays. The daily schedule includes learning about and managing with the symptoms of illness, vocational training, 
housekeeping, running errands and attending various social events. The Project is set up to intensify local community care and reduce the need for placements in psychiatric hospitals and nursing homes. The Project is run by a local non-governmental organisation (NGO) which is an accredited mental health service provider in the municipality. The NGO as a host organisation firmly regulates the organisational policies of the Project.

Given the fixed three-month duration of the Project's service periods, clients' subsequent living arrangements are an essential part of the Project's collaboration with local authorities, psychiatric hospitals, outpatient clinics, residential homes, and informal networks of clients. In line with Finnish mental health policy, the agencies involved in transitions share a common objective to move clients towards as independent living arrangement as possible. The scope of practice of the professionals of the Project entails making recommendations, jointly with their clients, about the preferred placement option. However, municipal authorities make the final decision, as they are responsible for the overall provision of services and coordination of client transitions. Consequently, we are not analysing the Project's professionals' boundary work as claims for decision-making rights, but as claims for making their recommendations valued when formal decisions are made by municipal authorities.

\section{Data Collection}

Professionals were recruited to the study by contacting both the Project and the board of directors of the NGO which granted the permission to collect data. The Project's six professionals, whose talk is analysed in this article, are made up of the following: an occupational therapist, a psychiatric nurse, a care worker with a bachelor's degree on social services and two practical nurses with vocational qualifications in social and health care. Despite different occupational backgrounds, all professionals conduct similar work with the clients and have equal status as team members. 
Data collection, conducted by the authors, aimed to reach the Project's professionals' discussions on transitions of clients. We collected data from 10 team meetings and four focus groups $^{i}$ from two consecutive service periods. As a routine part of the weekly schedule, team meetings were informal arenas in which professionals went over up-to-date situations of each client and planned their future living arrangements. Team meetings can be characterised as naturally occurring because they were not held for research purposes. The focus groups, however, were moderated by the authors. The interview schedule used in focus groups resembled the structure of the team meetings: one client at a time was freely discussed, with a special emphasis on his/her living arrangements. So, in the focus groups the professionals discussed the same clients as in the team meetings, but the timing was different: focus groups were conducted for the first time just after the service period was finished, and the second time focus groups took place three months after the service period had ended, as follow-up discussions. Both focus groups and team meetings provided a possibility to study the ways professionals reached shared understandings as a group (Morgan, 2002). The overall data corpus resulted in 14 audio-recorded, approximately one-hour discussions that were transcribed verbatim. The corpus includes all data from the two service periods of Project that the authors were permitted to participate.

\section{Data Analysis}

By viewing professionals' talk as mutually constructed in interaction (Juhila, Mäkitalo, \& Noordegraaf, 2014a), we are interested in how professionals, as a unified group, talk retrospectively about inter-agency negotiations on client transitions. We noted that in their talk, professionals positioned themselves mainly as representatives of the Project and thus as a united group, for example by using the word "we" a lot instead of "I". The shared nature of talk was also confirmed by silent practitioners expressing their agreement to the speaker by constant nodding (as observed in focus groups), or uttering frequent affirmative words like "yeah, yeah" to the practitioner talking at the time. These initial observations on professionals' talk as a 'joint endeavour' (Juhila et al. 2014a, 
p. 9) encouraged us to examine boundary work strategies as a means of obtaining organisational, rather than professional, jurisdiction arising from and occupational differences among staff members.

In the first phase of analysis, we used the method of descriptive coding (Gibbs, 2007, p. 149). More specifically, we formed broad descriptive categories to identify particular types of activities essential to our research inquiry (Hammersley and Atkinson 1983). As we were interested in clients' transitions to other services, we coded all instances of collaboration between the Project professionals and their collaborators $(\mathrm{N}=170)$. In the second phase we generated a more accurate view on collaboration by the means of interpretive coding (Gibbs, 2007, 150) which enabled us to divide these 170 instances into two groups according to the nature of collaboration: neutral/successful collaboration (126 instances) and disputed collaboration (64 instances).

In the third phase of analysis we continued interpretive coding by selecting the 64 disputed instances as core data of the study. In these instances the Project's professionals describe negotiations in which collaborators did not share their opinion but provided a competing viewpoint. The majority of disputes concern the dilemma between the Project's professionals who are in favour of more supported living and their collaborators who are in favour of more independent living. We chose disputes for a detailed analysis because different conflicts are regarded as an essential part of inter-agency collaboration, as organisations tend to strive to maintain their autonomy (Scott 1997). The richness of boundary work in the disputed instances can partly be explained by their capacity to “trigger" professionals to construct contrasts between their views and collaborators' views.

The disputed instances were read with theoretical understanding that was provided by the concept of boundary work as a rhetorical strategy in professional talk which demarcates insiders and outsiders (Allen 2000, p. 327; 2001, p. 85; Lamont \& Molnár 2002, p. 178; Riesch 2010, p. 3). Especially, we lean on Gieryn's (1983, p. 782) idea on boundary work as being scientists' strategy 
to create a positive public image for science by contrasting it favourably with non-scientific activities. Similarly, we paid attention to how the view of the Project's professionals' knowledge concerning client cases was contrasted favourably with the views of the collaborators.

Within this conceptual framework, we recognised boundary work primarily as making contrasts. The detailed examination of the contrasts showed that they are constructed by what we identify as "day-to-day evidence". We define day-to-day evidence as mundane observations which are founded on professionals' informal assessments on clients (Juhila, Saario, Gunther, \& Raitakari, 2014b). Day-to-day evidence includes perceptions of clients' condition and daily functioning that professionals collect when spending considerable time with clients during the intensive 3-month period. During that time they engage in many activities with clients, and thus become familiar with their current state of wellbeing and needs. Two types of this kind of evidence were discovered, and they are reported below.

\section{Ethical considerations}

The field work was started with the authors' presentations of the study for the staff and clients of Project. Information sheets of the study were distributed to them. Participation was voluntary and those who agreed to participate signed the consent forms, with a possibility to withdraw their consent at any stage. The study received an approval statement from the research ethics committee of the university where the study is based and complies with the Guidelines on Research Ethics by the Academy of Finland. During the whole research process, the study had a steering group consisting of both professional and service user members. We have anonymised the data examples presented in the results section so that localities and persons cannot be recognised. 


\section{Results}

In this section we illustrate the accomplishment of boundary work in professionals' talk on disputed inter-agency collaboration. It is reported how boundary work manifests as rhetorical contrasts that professionals construct between themselves and collaborative agencies.

\section{Boundary work as a contrastive strategy}

Below data examples are presented on two types of day-to-day evidence which are used as contrastive strategies of boundary work. The examples are taken from the 64 disputed instances that emerged from the descriptive coding of data. The examples ${ }^{\mathrm{ii}}$ are selected so that they address a crucial topic, both within the empirical data, and the field of supported housing more generally: the decision between independent or supported living arrangements after a short-term stay in a half way agency. Furthermore, the examples illustrate the most common collaborative agencies of the Project: municipal authorities, represented by a social worker, and residential homes which provide long-term supported housing. Moreover, in these examples the contrastive strategy of boundary work is used in an explicit way.

\section{Day-to-day evidence of a client's serious mental ill-health}

The negotiation, summarised below by a practical nurse of the Project, concerns a young woman who is soon to leave Project. According to the staff of the Project, the option of her starting to live alone in an ordinary rental flat is not appropriate. However, according to a municipal social worker, the client should move to the flat because she could manage there with additional support. In the extract below, day-to-day evidence of the client's serious mental ill-health is used as a strategy of boundary work to justify the point of view of the Project's professionals: 
We brought up the issue in the presence of the social worker that Isa's [fictive name of the client] living alone is not going to work out since during the entire Project which is three months she hasn't been able to stay in her own apartment for one single day, let alone night; we are talking about one hour that Isa has been able to spend there. You know Isa needs a lot of support for her own mental wellbeing, not so much for her skills to manage everyday life, but for being able to tolerate the anxiety and that state of fear. And there are a lot of delusions, from morning till evening, and they threaten to kill her, and Isa is depressed and distressed and weepy, and her condition has been bad during the entire Project ... (Social care worker 1, Focus group 1)

A range of day-to-day evidence is provided to support the Project's professionals' view that the client living alone in the apartment is not going to work. The evidence includes the client not being able to stay in her own apartment for longer than one hour at a time, the client having a lot of serious delusions and being heavily distressed; and the client's condition remaining bad all the way. The day-to-day evidence is further strengthened by extreme formulations of the social care worker, as she uses utterances such as "during the entire Project", "delusions from morning till evening"; "condition has been bad during the entire Project" (lines 2, 7 and 8 of the excerpt). Day-to-day evidence supports the view of Project staff that due to considerable ill-health, Isa cannot manage living on her own but needs supported living. Next, the social care worker of the Project moves on to describe the contrasting view of the municipal social worker:

The social worker ends the meeting by saying that Isa has rehabilitated well compared to what she has seen of her before, and the plan is now that Isa will move into her own apartment after the Project, and it is possible to get some support from the outpatient clinic; like groups and the floating support team which will then go and check up on Isa. And the 
social worker is very talented in talking. She says to Isa that you look really good, and it is clear that you are in better shape than before, and there are all kinds of fancy stuff that could be set up in your apartment. [It could be] decorated so that it feels more like home, that of course she [the social worker] understands that the apartment does not necessarily feel like home yet, but once some carpets and curtains and the like are brought, whatever you yourself would like, and then when you decorate it the way you would like then it will start to feel more like home. (Social care worker 1, Focus group 1)

The Project's social care worker describes the personal features of the social worker, calling her "talented in talking" (line 5 of the excerpt), and portrays her as talking over the staff of the Project, addressing her arguments straight to Isa who took part in the negotiation. The care worker cites the words of the social worker with a slight parodying nuance (the last seven lines of the excerpt). In the present case, the reported speech conveyed that according to the social worker, Isa is able to live alone with the right kind of support and decoration. The social care worker uses reported speech to demonstrate that the social worker was not up-to-date with the seriousness of Isa's condition. While the Project's professionals pose themselves as holders of day-to-day evidence of Isa's current serious ill-health, the collaborator is presented as lacking this evidence.

\section{Day-to-day evidence of a client's inadequate living skills}

The next example, summed up by a psychiatric nurse of the Project, demonstrates another strategy of boundary work, which draws on the Project's professionals as owners of evidence of the client's inadequate living skills. The psychiatric nurse talks about a young man who came to the Project from a residential home. The plan was that after the Project he would start living in an ordinary rental flat. At first, the Project's professionals went along with this plan, but then, in the light of the 
day-to-day evidence they gathered, changed their minds in favour of more supported living arrangements:

Erik [fictive name of the client] came to us from [a residential home] where they had already done the applications for an apartment and it was discussed, that after the Project Erik would transfer totally into independent living. And there was not much talk about any support for that, but the apartment was being looked for on the open market. We then renewed these applications. Immediately when Erik came [to the Project] we started to apply for an apartment. But then in the two last weeks before the Project ended, we were all like really amazed at how weak he was in all kinds of daily living skills. The lad didn't know how to cook porridge and could not tell whether was ready or not, and he didn't know how to clean, nothing really was working. And even though we were informed that he knows how to independently move from one place to another, well that independent moving meant that he moved from place A to place B. He didn't have any other routes but the one he could manage. Only during the course, when we started to map his abilities, we gained all the time new insights that this or this is not working. (Psychiatric nurse 1, Focus group 3)

Again, boundary work is accomplished by contrasting, but this time grounded with a different kind of evidence, i.e., the client's inadequate living skills. The psychiatric nurse of the Project describes how they start to undermine the view of residential home's staff by presenting day-to-day evidence on inadequate everyday skills of Erik, for example, his moving from place to place, cleaning and cooking. Again, this view is backed up by extreme formulations, such as "we were all really amazed ", "in all kinds of daily living skills", nothing really was working”, "we gained all the time new insights" (lines 6-9 of the excerpt). This way, the residential home's plan for Erik to live alone in a rental flat is undermined by the ample day-to-day evidence gathered by the professionals during the Project. 


\section{Discussion}

This article suggested that mental health professionals use day-to-day evidence as a strategy of boundary work in inter-agency client transitions. Professionals construct two types of day-to-day evidence with which they aim to influence decisions on clients' living arrangements: firstly, evidence on the seriousness of clients' mental ill-health, and secondly, clients' inadequate living skills. This mundane 'evidence' is based on rhetorical contrasts: professionals pose their collaborators as lacking day-to-day evidence of practical and up-to-date observations and hence have incomplete understanding of clients' needs. The contrasts are further emphasised by what Pomeranz (1986) calls extreme formulations, i.e. excessive utterances that professionals use to legitimise their claims. At the same time, the Project's professionals themselves claim to be aware of the current needs of the clients. Therefore, day-to-day evidence portrays the Project's professionals as the convincing "owners" of this particular kind of mundane knowledge.

These two discovered boundary work strategies have particular functions: firstly, to reach the most appropriate living arrangement for a client after discharge, and secondly, to boost the Project's authority as an expert agency on recommending the placements. In the latter function, the significance of boundary work lies in strengthening the Project's credibility as a worthy service. With fixed duration, less established ways to collaborate and uncertain prospects of becoming an established agency in the field, the Project's professionals' boundary work serves to establish their service as being as indispensable as possible (Hall, Slembrouck, Haigh, \& Lee, 2010, p. 356).

In organisational theory, agencies' tendency to compete for resources and evolve accordingly has long been acknowledged (Scott, 1997; Singh, 1990). As Hernes (2004, p. 10) states, boundaries are not 'by-products' of an organisation, but rather an organisation evolves through the processes of boundary setting. Like any social system, an organisation emerges through 
processes of drawing distinctions, and it persists through the reproduction of boundaries. Our findings show one way of promoting one's organisation: the boundary work of contrastive rhetoric.

The finding that boundary work manifests as a rhetorical strategy endorses Gieryn's (1983) idea on boundary work as a means to contrast one's image favorably to others. Contrasts building on the possession of day-to-day evidence resonate also with Smith's (1978) study where similar types of evidence (i.e. everyday perceptions of a person's behaviour) are called “contextual factors". Smith demonstrated how, by adding appropriate contextual factors to the description of a person's mental ill-health, one can encourage others to see anomalies in that person's behaviour. If the same behaviour is described without these contextual factors, others will not necessarily see it as anomalous at all (Smith, 1978).

Empirical research using Abbott's $(1995 ; 1988)$ theory on professional boundaries has reported various functions of boundary work within professions and individual professionals. Allen (2000) and Håland (2012), for instance, note that boundary work enabled the construction of more symmetrical relations between nurses and doctors. Cameron (2011) suggests that the boundaries between professions are breaking down towards something that can be termed as the introduction of the "generic worker". We conclude that while professions are merging, organisations remain (in some form at least), and thus professionals continue to identify themselves as representatives of their own organisation. This makes it essential to focus on "organisational jurisdiction" and how it is achieved, alongside with the established concept of "occupational jurisdiction". One timely example of this orientation is Wong, Breiner, and Mylopoulos's (2014) study on the relations between hospital-based and community-based health programmes.

To understand the subtleties by which professionals employ boundary work to obtain jurisdiction for their own organisation is crucial also for successful client transitions. The way transitions are managed is prominent for clients because, as Leach and Hall (2011, p. 141) note, 
transitions tend to raise a lot of anxieties. Once leaving the current service one faces major changes in everyday life, including new people, routines and contexts to which one needs to adjust. Accordingly, mental health policy guidelines acknowledge the importance of collaboration and harmonisation between services (e.g., Ministry of Social Affairs and Health, 2010; Schneider, Carpenter, \& Brandon, 1999). Breaches occurring in what are supposed to be "seamless services" are unwanted (Rogler \& Dharma, 1993).

The limitations of this article are in the small-scale data set, which consist of professionals' discussions. Clients' voice were absent in the data and thus their role became visible only from the professionals' point of view. In their talk, professionals aligned themselves with clients, by stating that they are the ones who know best clients' current needs. Furthermore, data on retrospective talk does not reach interaction between participants in real life encounters. However, the data enabled us to effectively capture professionals' jointly constructed reflections on the position of their service in inter-agency client transitions. As such, the analysis succeeded in reporting the ways professionals make sense of complex and dynamic boundaries in inter-agency collaboration (Chong, Asiani, \& Cheng, 2013; Scott, 1997).

\section{Conclusions}

As a means to constitute knowledge upon which professionals build their authority, boundary work inevitably addresses power relations between different stakeholders. This article illustrated boundary work accomplished in such a service where professionals have daily contact with their clients and thus know them well. Drawing on the argument of the World Health Organisation (2010) to include a wide range of professionals in healthcare teams, we ask the following: To what extent are these professionals, that are most familiar with the current status of their clients, included in decisions on client transitions? What is the significance of the day-to-day 
evidence as a means of boundary work? Inter-agency disputes revolve ultimately around the question of who has the most relevant understanding about the client case.

Scott (1997) points out that framing collaboration primarily as an inter-professional issue brings out the differences in professional values, power and knowledge. While these are important dimensions, this article has pursued to recognise the significance of the organisational mandate of agencies (Wong, Breiner, \& Mylopoulos, 2014). In this sense, further studies on boundary work as a means of obtaining organisational jurisdiction can aid in theorising the numerous boundaries present in care work (Llewellyn, 1998).

\section{References}

Abbott, A. (1995) Boundaries of Social Work or Social Work of Boundaries? Social Service Review, 69(4), 545-562.

Abbott, A. (1988) The system of professions. An Essay on the division of expert labor. Chicago: University of Chicago Press.

Allen, D. (2000) Doing Occupational Demarcation: The "Boundary Work" of Nurse Managers in a District General Hospital. Journal of Contemporary Ethnography, 29(3), 326-356.

Allen, D. (2001) Narrating Nursing Jurisdiction: “Atrocity Stories" and "Boundary-Work". Symbolic Interaction, 24(1), 75-103.

Cameron, A. (2011) Impermeable boundaries? Developments in professional and inter-professional practice. Journal of Interprofessional Care, 25(1), 53-58.

Chong, W.W., Aslani, P., Chen T.F. (2013) Shared decision-making and interprofessional collaboration in mental healthcare: a qualitative study exploring perceptions of barriers and facilitators. Journal of Interprofessional Care, 27(5), 373-379. 
Fakhoury, W. \& Priebe, S. (2002) The process of deinstitutionalization: an international overview. Current Opinion in Psychiatry, 15, 187-192.

Fournier, V. (2000) Boundary work and the (un)making of the professions. In N. Malin (Ed.) Professionalism, Boundaries and the Workplace. London: Routledge.

Gachoud, D., Albert, M., Kuper, A., Stroud, L., Reeves, S. (2012) Meanings and perceptions of patient-centeredness in social work, nursing and medicine: A comparative study. Journal of Interprofessional Care, 26(6), 484-490.

Gibbs, G. (2007) Analyzing Qualitative Data. The SAGE Qualitative Research Kit. Los Angeles: Sage.

Gieryn, T. (1983) Boundary Work and the Demarcation of Science from Non-science: Strains and Interests in Professional Ideologies of Scientists. American Sociological Review, 48, 781-795.

Hall, C., Slembrouck, S., Haigh, E., Lee, A. (2010) The Management of Professional Roles during Boundary Work in Child Welfare. International Journal of Social Welfare, 19(3), 348-357.

Hammersley, M., Atkinson, P. (1983) Ethnography: Principles in Practice. London: Tavistock.

Hernes, T. (2004) Studying Composite Boundaries: A Framework of Analysis. Human Relations, 57(1), 9-29.

Håland, E. (2012) Introducing the electronic patient record (EPR) in a hospital setting: boundary work and shifting constructions of professional identities. Sociology of Health and Illness, 34(5), $761-775$.

Juhila, K., Mäkitalo, Å., Noordegraaf, M. (2014a) Analysing social work interaction. Premises and approaches. In C. Hall \& K. Juhila \& M. Matarese \& C. van Nijnatten (Eds.) Analysing Social Work Communication. Discourse in practice. Routledge: London and New York.

Juhila, K., Saario, S., Gunther, K., Raitakari, S. (2014b) Reported client-practitioners conversations as assessment in mental health practitioners' talk. Text \& Talk, 34(1), 69-88. 
Knapp, M., Beecham, J., McDaid, D., Matosevic, T. (2011) The economic consequences of deinstitutionalisation of mental health services: lessons from a systematic review of European experience. Health and Social Care, 19(2), 113-125.

Lamont, M. \& Molnár, V. (2002) The Study of Boundaries in the Social Sciences. Annual Review of Sociology, 28(1), 167-195.

Leach, J. \& Hall, J. (2011) A city-wide approach to cross-boundary working with students with mental health needs. Journal of Interprofessional Care, 25(2), 138-144.

Llewellyn, S. (1994) Managing the boundary: how accounting is implicated in maintaining the organisation. Accounting, Auditing and Accountability Journal, 7(4), 4-23.

Llewellyn, S. (1998) Boundary work: Costing and caring in the social services. Accounting, organisations and society, 23(1), 23-47.

Ministry of Social Affairs and Health (2010) Plan for mental health and substance abuse work. Reports of the Ministry of Social Affairs and Health no 5, Helsinki.

Morgan, D. (2002) Focus group interviewing. In J. Gubrium \& J. Holstein (Eds.) Handbook of interview research. Context \& method. Thousand Oaks, CA: Sage, 141-159.

Mossberg, L. (2013) Strategic collaboration as means and ends: views from members of Swedish mental health strategic collaboration councils. Journal of Interprofessional Care, 28(1), 58-63.

Pomeranz, A. (1986) Extreme Case Formulations: A Way of Legitimising Claims. Human Studies, 9, 219-229.

Riesch, H. (2010) Theorizing Boundary Work as Representation and Identity. Journal for the Theory of Social Behaviour, 40(4), 452-473. 
Rogler, L. \& Dharma, E. (1993) Help-seeking Pathways: A Unifying Concept in Mental Health Care. American Journal of Psychiatry, 150(4), 554-561.

Rose, N. (1999) Powers of Freedom. Reframing Political Thought. Cambridge: Cambridge University Press.

Sanders, T., Harrison, S. (2008) Professional legitimacy claims in the multidisciplinary workplace: the case of heart failure care. Sociology of Health \& Illness, 30(2), 289-308.

Scott, D. (1997) Inter-agency conflict: an ethnographic study. Child and Family Social Work, 2(2), 73-80.

Schneider, J., Carpenter, J., Brandon, T. (1999) Operation and organisation of services for people with severe mental illness in the UK. A survey of the Care Programme Approach. The British Journal of Psychiatry, 175, 422-425.

Singh, J. (1990) Organisational Evolution. Newbury Park: Sage Publications.

Slembrouck, S. \& Hall, C. (2014) Boundary work. In C. Hall \& K. Juhila \& M. Matarese \& C. van Nijnatten (Eds.) Analysing Social Work Communication. Discourse in practice. Routledge: London and New York.

Smith, D. (1978) 'K is mentally Ill' the Anatomy of a Factual Account. Sociology, 23(12), 23-53.

Yin, R. (1994) Case Study Research. Design and Methods. Applied Social Research Series. Volume 5. Second edition. SAGE Publications: London.

Wikström, E. (2008) Boundary Work as Inner and Outer Dialogue: Dieticians in Sweden. Qualitative Research in Organizations and Management, 3(1), 59-77. 
World Health Organisation (2010) Framework for Action on Interprofessional Education \& Collaborative Practice. Retrieved from:

http://whqlibdoc.who.int/hq/2010/WHO_HRH_HPN_10.3_eng.pdf?ua=1)

Wong, R., Breiner, P., Mylopoulos, M. (2014) Shifting contours of boundaries: an exploration of inter-agency integration between hospital and community interprofessional diabetes programs. Journal of Interprofessional Care, 28(5), 447-452.

'All Project professionals attended to team meetings and focus groups. iThe examples are translated from Finnish to English. 